\title{
O COLÉGIO DE APLICAÇÃO/UFRGS E A DIFUSÃO DAS CLASSES EXPERIMENTAIS SECUNDÁRIAS: ENTRE O ARQUIVO E A MEMÓRIA ORAL (1959-1981)
}

\author{
Valeska Alessandra de Lima' \\ 'Universidade Federal do Rio Grande do Sul (Ufrgs), Porto Alegre/RS, Brasil \\ Doris Bittencourt Almeida" \\ "Universidade Federal do Rio Grande do Sul (Ufrgs), Porto Alegre/RS, Brasil
}

$\cos 8$

\begin{abstract}
Resumo
$\mathrm{O}$ artigo investiga memórias do Colégio de Aplicação (CAp/Ufrgs), instituição de ensino que se constituiu como uma espécie de vanguarda pedagógica na sociedade porto-alegrense. Discute-se a implantação das classes experimentais secundárias, como uma apropriação das Classes Nouvelles francesas. Documentos orais e arquivísticos foram examinados e permitem inferir que o CAp é produto do seu tempo, representa a propagação dos discursos de renovação educacional, sobretudo os estudos de Psicologia que passaram a ocupar espaço relevante nas questões escolares e na formação de professores. As práticas educativas do CAp evidenciam a circularidade cultural entre educadores, especialmente franceses e brasileiros que, por muitos anos, estiveram ligados pelas missões e intercâmbios pedagógicos.

Palavras-chave: classes experimentais secundárias, Colégio de Aplicação, memórias docentes.
\end{abstract}

\section{EL COLEGIO DE APLICACIÓN/UFRGS Y LA DIFUSIÓN DE CLASES SECUNDARIAS EXPERIMENTAL: ENTRE EL ARCHIVO Y LA MEMORIA ORAL (1959-1981)}

\section{Resumen}

El artículo investiga memorias del Colegio de Aplicación (CAp/Ufrgs), institución de enseñanza que se constituyó como una especie de vanguardia pedagógica en la sociedad porto-alegrense. Se discute la implantación de las clases experimentales secundarias, como una apropiación de las Clases Nouvelles francesas. Los documentos orales y archivísticos fueron examinados y permiten inferir que el CAp es producto de su tiempo, representa la propagación de los discursos de renovación educativa, sobre todo los estudios de Psicología que pasaron a ocupar espacio relevante en las cuestiones escolares y en la formación de profesores. Las prácticas educativas del CAP evidencian la circularidad cultural entre educadores, especialmente franceses y brasileños que, durante muchos años, estuvieron ligados por las misiones e intercambios pedagógicos.

Palabras clave: clases experimentales secundarias; Colegio de Aplicación, memorias docentes. 
THE COLLEGE OF APPLICATION/UFRGS AND THE DIFFUSION OF EXPERIMENTAL SECONDARY CLASSES: BETWEEN THE FILE AND THE ORAL MEMORY (1959-1981)

\begin{abstract}
The article investigates memories of the College of Application (CAp/Ufrgs), an educational institution that was established as a sort of pedagogical vanguard in the Porto Alegre society. We discuss the implementation of the secondary experimental classes, as an appropriation of the French Nouvelles Classes. Oral and archival documents were examined and allowed to infer that the CAp is the product of his time, represents the propagation of discourses of educational renewal, especially the studies of Psychology that have come to occupy relevant space in school issues and teacher training. The educational practices of the CAp show the cultural circularity between educators, especially French and Brazilian, who for many years were linked by the missions and pedagogical exchanges.

Keywords: secondary experimental classes, College of Application, teaching memories.

\section{LE COLLEGE D'APPLICATION/UFRGS ET LA DIFFUSION DES CLASSES SECONDAIRES EXPERIMENTALES: ENTRE LE FICHIER ET LA MEMOIRE ORALE (1954-1981)}

\title{
Résumé
}

L'article étudie des souvenirs de lycée (CAp/Ufrgs), établissement d'enseignement qui est formé comme une sorte d'enseignement à l'avant-garde dans la société de Porto Alegre. II traite de l'implémentation des classes secondaires expérimentales, en s'appropriant les Nouvelles Classes françaises. Des documents orales et d'archivage ont été examinés et permettent de déduire que la PAC est un produit de son temps, représente la propagation de discours de renouveau éducatif, en particulier ses études de Psychologie qui est venu à occuper l'espace dans le scolastique et des questions relatives à la formation de enseignants. Les pratiques éducatives de la PAC montrent la circularité entre éducateurs culturels, en particulier les Français et les brésiliens qui, pendant de nombreuses années, ont été liés par les missions et les échanges éducatifs. Mots-clés: classes secondaires expérimentales, Colégio de Aplicação, memoire d'enseignant. 


\section{O Colégio de Aplicação/Ufrgs e a instalação de um ensino laboratorial}

ste estudo tematiza o Colégio de Aplicação (CAp) da Universidade Federal
do Rio Grande do Sul (Ufrgs), tendo como corpus documental narrativas de
professoras $^{1}$, bem como outros documentos ${ }^{2}$ localizados. Tem-se como objetivo investigar práticas educativas disseminadas no Colégio de Aplicação da Ufrgs, no período de 1959 a 1981,notadamente a implantação das classes experimentais secundárias, em suas interfaces com a constituição de um determinado ideal de escola na sociedade porto-alegrense, sem perder de vista as conexões com os movimentos internacionais de renovação educacional.

Desse corpus documental, emergem experiências pedagógicas desenvolvidas no CAp, muitas delas vistas como inovadoras para a época, que auxiliam na tentativa de compreender esta instituição e seus processos educativos, dos quais, em boa parte, somos herdeiros. Inscrita no campo da História da Educação, a pesquisa destaca aspectos singulares dessa instituição educativa e considera a importância dos agentes educacionais.

O Colégio de Aplicação da Ufrgs foi fundado em 1954, pela Faculdade de Filosofia, vinculado ao Departamento de Educação. Entre seus objetivos, buscava promover a prática docente de estagiários dos Cursos de Licenciatura da Universidade, bem como, legitimarse como campo de investigação pedagógica. (SCHÜTZ, 1994). Em 1971, logo após a Reforma Universitária ${ }^{3}$, a Faculdade de Filosofia teve seus cursos desmembrados, fato que promoveu a constituição da Faculdade de Educação como unidade acadêmica. À nova Faculdade coube o Colégio de Aplicação como um Órgão Anexo a ela e com o qual dividiu, até 1996, um prédio construído pelo Instituto Nacional de Estudos Pedagógicos (Inep) ${ }^{4}$ no Campus Central.

Embora, a partir de 1971 o CAp passasse a integrar a Faculdade de Educação (Faced), ambas as instituições operavam acadêmica e administrativamente de modos distintos, apenas dividiam o mesmo edifício e, muitas vezes, as mesmas docentes. Um aspecto interessante é que, enquanto a Faced fazia eleições para Direção a cada quatro anos, o Colégio teve a presença constante de Graciema Pacheco, por vinte e sete anos à frente da instituição. Ao lado dela, estava Isolda Holmer Paes, como Vice-Diretora, por cerca de vinte anos. Durante o período desta primeira gestão, um conjunto de inovações educacionais foi empreendido após convênios firmados com o Inep. Assim, a escolha pelo recorte temporal da pesquisa, está situada entre 1959e 1981, período em que as Classes Experimentais Secundárias fizeram parte dos programas educativos do CAp, que concentrava esforços para a manutenção de um tipo de escola voltada a um determinado público.

Pesquisas em instituições educativas, de acordo com Gatti Jr. (2002) são

\footnotetext{
${ }_{1}^{1}$ Para esta pesquisa, foram entrevistadas cinco professoras que atuaram no CAp ao longo dos seus primeiros trinta anos. Também foram consultadas entrevistas com Graciema Pacheco e Isolda Holmer Paes, primeiras diretora e vice-diretora da instituição, respectivamente, além de artigos escritos por Isolda Paes.

2 Estes documentos encontram-se localizados no Arquivo da Faculdade de Educação da Ufrgs e no Arquivo da Comissão de Ensino (Comen) do Colégio de Aplicação/Ufrgs.

${ }^{3}$ Reforma Universitária de 1968, Lei 5.540 (28/11/1968).

4 O Inep possuiu diferentes nomes desde sua criação: Instituto Nacional de Pedagogia (1937), Instituto Nacional de Estudos Pedagógicos (1938), Instituto Nacional de Estudos e Pesquisas Educacionais (1972) e, por fim, Instituto Nacional de Estudos e Pesquisas Educacionais Anísio Teixeira (2001) em reconhecimento pelos anos que o professor Anísio Teixeira, esteve à frente do Instituto, proporcionando a expansão e privilegiando o desenvolvimento da pesquisa educacional.
} 
investigações que ocorrem em seus interiores pela "apreensão daqueles elementos que conferem identidade às escolas, ou seja, daquilo que lhes confere um sentido único no cenário social, mesmo que elas tenham se transformado no decorrer dos tempos". (GATTI JR., 2002, p. 20). Para o autor, vários dispositivos ${ }^{5}$ constituem uma instituição deste tipo, dentre eles se destacam aspectos como a ação educativa em si e os sujeitos que dela fazem parte. Magalhães (2004) explica que é pelo uso das memórias e do arquivo, que se pode construir uma narrativa coerente sobre a identidade histórica da instituição, ao valorizar as diferentes fontes que podem ser contrastadas por meio dos vestígios conservados do passado.

Conhecer o Colégio de Aplicação da Ufrgs implicou em mergulhar no seu interior para tentar interpretar os sentidos desta instituição educativa, bem como perceber suas peculiaridades expressas nos valores, atitudes e saberes por ele construídos. Tínhamos a convicção que era preciso escutar as professoras, apostando na História Oral como metodologia. Produziram-se, assim, entrevistas com cinco docentes que atuaram nos primeiros trinta anos do Colégio e que estavam dispostas a rememorar o passado vivido na instituição.

Enquanto as entrevistas ocorriam, fizemos outros movimentos no sentido de procurar informações ${ }^{6}$ referentes às memórias das antigas diretoras do Colégio, bem como de localizar documentos relativos às práticas educativas lá desenvolvidas, práticas essas anunciadas pelas professoras. Nessa busca, encontramos documentos que tratam das Classes Experimentais, a partir das experiências francesas no Centre International d'études Pédagogiques (ROCHA, 1982), onde a professora Isolda Paes realizou estágio7 ${ }^{7}$, em 1953.

Pela análise desses indícios, constatou-se que havia diante de nós um Colégio de Aplicação interessado em qualificar seus processos pedagógicos, que se esforçava em legitimar-se como um centro de pesquisa educacional, fazendo jus aos investimentos do Inep. Enfim, esta amostra documental possibilita indagar algumas das concepções educacionais que circulavam naquele contexto, além de permitir a análise de elementos da cultura escolar presentes nas Classes Experimentais Secundárias.

O levantamento de informações orais e arquivísticas sobre o Colégio de Aplicação da Ufrgs demonstrou que, para uma melhor compreensão de sua história, se faz necessário conhecer outros movimentos que conduziram até sua implantação. Portanto, não há como falar desta instituição sem considerar os discursos de renovação educacional que chegavam ao Brasil, sobretudo os estudos de Psicologia que passaram a ocupar espaço relevante nas questões escolares e na formação dos professores. Pode-se dizer que a criação do Colégio de Aplicação/Ufrgs é tributária à difusão da Psicologia como um aporte

${ }^{5} \mathrm{O}$ conceito de dispositivo em Foucault está vinculado aos aspectos genealógicos de sua obra e se relaciona à discussão de poder. Uma definição possível de dispositivo afirma que "dispositivo é a rede de relações que podem ser estabelecidas entre elementos heterogêneos: discursos, instituições, arquitetura, regramento, leis, medidas administrativas, enunciados científicos, proposições filosóficas, morais, filantrópicas. o dito e o não dito. o dispositivo estabelece a natureza do nexo que existe entre esses elementos heterogêneos". (FOUCAULT, 1977, p.301).

${ }^{6}$ Entre os documentos conservados na instituição estão Relatórios e ofícios da Secretaria de Educação que regulamentam a implantação das Classes Experimentais, além do Plano para Organização das Classes Experimentais no CAp, escrito pela Direção do Colégio em 1961. Outras fontes utilizadas foram entrevistas concedidas por Graciema Pacheco e Isolda Paes a jornais e revistas científicas. (GOMES, 2003; PACHECO, 1974; HACKMANN, 2004; PAES, 1983; 1994).

7 Isolda Holmer Paes formou-se, em Letras Neolatinas na Universidade do Rio Grande do Sul, em 1947. 
para o trabalho pedagógico.

Graciema Pacheco teve os primeiros contatos com lições de Psicologia na condição de aluna da Escola Complementar ${ }^{8}$. Recordou os estudos na cadeira de Psychologia, sob a regência da professora Natércia Cunha Velloso ${ }^{9}$ (1892-1975) que, segundo ela "não dava bibliografia, ditava os pontos" (GOMES, 2003) da lição. Anos mais tarde, Graciema identificou tais lições com a obra de William James, um dos fundadores da Psicologia Moderna. E acrescentou ao seu repertório de leituras, autores como Thorndike, Piaget, Claparède, Decroly, Binet e, principalmente, Lourenço Filho ${ }^{10}$. (ALMEIDA; LIMA, 2015).

Entende-se que a formação de Graciema teve ressonância na constituição do CAp/Ufrgs, pois, como professora das cadeiras de Didática, juntamente com Leonardo Tochtrop ${ }^{11}$, foi autorizada pela direção da Faculdade de Filosofia, a organizar, em 1947, um Ginásio de Aplicação da Universidade do Rio Grande do Sul (Urgs) ${ }^{12}$.Entretanto, foi efetivamente a partir de 1954 que o CAp iniciou suas atividades, tendo Graciema Pacheco e Isolda Paes, Diretora e Vice, respectivamente. (REGNER, 1993). O regulamento da instituição tinha a finalidade de "ministrar o ensino secundário a seus alunos; servir à prática docente e aos estágios dos alunos dos cursos de Licenciatura e, servir de campo de investigação pedagógica para a Faculdade de Filosofia". (REGNER, 1993, p. 33).

Isolda Paes (1994) afirma que o grupo de professores que participou da implantação do CAp nutria o desejo de empreender significativas modificações na abordagem dos conteúdos ministrados. Assim, avalia a escola de seu tempo, "exaurida, era uma escola cansada. Ela repetia ano após ano, sempre as mesmas experiências com os alunos [...]" (PAES, 1994, p. 17). A aposta era outra com a implementação de um Colégio de Aplicação.

De acordo com artigo publicado por Isolda Paes na Revista Educação e Realidade/Ufrgs, em 1983, infere-se que havia intenção de fomentar a criatividade na escola. Neste sentido, destaca a importância da promoção de atividades, tais como: teatros, saraus e pinturas no pátio e pela cidade. Podemos imaginar que essas práticas permitissem aos estudantes transitar, de certo modo, livres pelo campus da Universidade. Contudo, embora o Colégio tenha sido idealizado pela Faculdade para servir de campo de experimentação pedagógica, é possível perceber pelas palavras da Vice-Diretora, o quão conflituoso deve ter sido este período de convívio entre gerações diferentes dividindo o mesmo espaço do campus, pois, enquanto os mais jovens

${ }^{8}$ A denominação desta escola iniciou como Escola Normal da Província de São Pedro (1869); depois Escola distrital de Porto Alegre (1901); Escola Complementar (1906); Escola Normal (1929); Escola Normal General Flores da Cunha (1937); Instituto de Educação (1939); Instituto de Educação General Flores da Cunha (1959) e, Centro Estadual de Formação de Professores General Flores da Cunha (2003). (WERLE, 2005).

9 Natércia Cunha Velloso foi aluna da Escola Complementar em 1915. Lecionou na instituição em 1925, regendo as disciplinas de Psychologia e de Direito Pátrio. Foi também, Poetisa e membro da Academia Literária Feminina do Rio Grande do Sul. Publicou, entre outros, os livros Teia de Sonhos (1950) e Messe Outonal (1952). (GOMES, 2003). Disponível em: <http://www.ufrgs.br/museupsi/PSI-RS/Chap4.htm>.

10 Lourenço Filho foi um intelectual pioneiro na introdução e disseminação dos conhecimentos psicológicos no campo educacional brasileiro.

11 Dicionarista e professor. Foi o primeiro titular da Cátedra de Didática Geral e Especial da Faculdade de Filosofia da Ufrgs.

12 Em 1947, aconteceu a alteração da nomenclatura de Universidade de Porto Alegre para Universidade do Rio Grande do Sul. 
[...] explodiam em criatividade e saudável alegria, os austeros professores da Faculdade de Filosofia, iam organizando o coro da insatisfação: "criança não anda de elevador; a Faculdade não é lugar para criança; descem escadas correndo e barulhando... pulam no terraço (faziam ginástica no terraço) e perturbam as aulas do $3^{\circ}$ andar". (PAES, 1983, p. 78).

Pode-se, hoje, questionar esta posição dos adultos avessa ao convívio com crianças e adolescentes, se considerarmos o fato de que os licenciandos estudavam, justamente, para formarem-se professores. Todavia, há também que se considerar 0 caráter ficcional da narrativa de memória, pois essa entrevista ocorreu anos após o fim de seu trabalho no CAp e, deste modo, entende-se sua rememoração como uma representação acerca do vivido em tal contexto.

Tendo em vista esses aspectos observados, temos diante de nós um Colégio de Aplicação que contou coma presença efetiva de Graciema Pacheco e Isolda Paes à sua frente, mulheres que exerceram não só encargos de direção no CAp, mas se constituíram em referências na condução de diferentes práticas educativas associadas aos estudos de Psicologia.

\section{O CAp/Ufrgs pelas palavras de suas professoras}

É importante dizer quem são as professoras que se dispuseram a falar nesta pesquisa. A seguir, o Quadro 01 as identifica e apresenta alguns dos lugares por elas ocupados em diferentes momentos, inclusive de onde falam no presente. Para respeitar suas identidades, atribuímos pseudônimos ${ }^{13}$ de pássaros: Rouxinol, Sabiá, Pardal, Bem-tevi e Cardeal.

Quadro1 - Informações sobre as professoras entrevistadas.

\begin{tabular}{|l|l|l|l|l|l|l|}
\hline \multirow{2}{*}{ PROFa } & \multirow{2}{*}{ NASCIM. } & \multicolumn{2}{|c|}{ FORMAÇÃO } & \multicolumn{2}{c|}{$\begin{array}{c}\text { PERÍODO EM QUE } \\
\text { ESTEVE NO CAp }\end{array}$} & \multirow{2}{*}{ SITUAÇÃO ATUAL } \\
\cline { 3 - 6 } & CURSO & $\begin{array}{l}\text { INSTI- } \\
\text { TUIÇÃO }\end{array}$ & ALUNA & DOCENTE & \\
\hline Rouxinol & Porto Alegre & $\begin{array}{l}\text { História } \\
(1972)\end{array}$ & Ufrgs & $1966-1968$ & $1972-1983$ & $\begin{array}{l}\text { Aposentada Ufrgs } \\
\text { Profä. titular PPG Inst. Privada }\end{array}$ \\
\hline Pardal & Porto Alegre & $\begin{array}{l}\text { Ciências } \\
\text { Sociais } \\
(1968)\end{array}$ & PUC-RS &.-- & $1970-1983$ & $\begin{array}{l}\text { Aposentada Ufrgs } \\
\text { Colaboradora PPG Inst. } \\
\text { Privada }\end{array}$ \\
\hline
\end{tabular}

${ }^{13} \mathrm{~A}$ escolha dos codinomes justifica-se em função do Termo de Consentimento Informado, apresentado às professoras no momento da entrevista, destacar que seus nomes seriam preservados. Portanto, diante deste compromisso da pesquisa, para identificá-las buscou-se inspiração no Acervo de Memórias Orais do Arquivo da Faculdade de Educação/Ufrgs. No referido Acervo, atribuíram-se aos entrevistados a identificação de árvores típicas do Rio Grande do Sul, que se encontram nas imediações do prédio da Faculdade, no Campus Central da Ufrgs. Nesta investigação, considerando as relações que se estabelecem entre o Colégio de Aplicação e a Faculdade de Educação, elegemos nomes de aves para nomear as narradoras, pois, metaforicamente, entende-se que atuaram como agentes polinizadores, de certo modo, propagaram conhecimentos adquiridos na Ufrgs para outros espaços de educação com os quais se envolveram. 


\begin{tabular}{|c|c|c|c|c|c|c|}
\hline \multirow{2}{*}{ PROFa } & \multirow{2}{*}{ NASCIM. } & \multicolumn{2}{|c|}{ FORMAÇÃO } & \multicolumn{2}{|c|}{$\begin{array}{l}\text { PERÍODO EM QUE } \\
\text { ESTEVE NO CAp }\end{array}$} & \multirow{2}{*}{ SITUAÇÃO ATUAL } \\
\hline & & CURSO & $\begin{array}{l}\text { INSTI- } \\
\text { TUIÇÃO }\end{array}$ & ALUNA & DOCENTE & \\
\hline Bem-te-vi & Porto Alegre & $\begin{array}{l}\text { Letras, } \\
\text { Francês } \\
\text { (1964) }\end{array}$ & Ufrgs & $1954-1960$ & $1965-1972$ & $\begin{array}{l}\text { Aposentada Ufrgs } \\
\text { Profa. Titular PPG em Univ. } \\
\text { Fed. em SP }\end{array}$ \\
\hline Sabiá & Torres & $\begin{array}{l}\text { Filosofia } \\
(1960)\end{array}$ & Ufrgs &.-- & $1960-1980$ & Aposentada Ufrgs \\
\hline Cardeal & Porto Alegre & $\begin{array}{l}\text { Pedagogia } \\
(1964)\end{array}$ & Ufrgs &.-- & $1965-1985$ & Aposentada Ufrgs \\
\hline
\end{tabular}

Fonte: Acervo de memórias orais - Arquivo da Faculdade de Educação/Ufrgs.

As tramas produzidas pelas narrativas destas mulheres carregam marcas de seus percursos e são analisadas a partir do conteúdo discursivo expresso. São suas experiências, não só enquanto professoras do CAp, mas como pesquisadoras da educação que influenciaram na composição do que disseram. Como todo documento, os depoimentos precisaram ser examinados, pois neles há evidências das diferentes relações que atravessaram sua constituição.

Parecem oriundas de famílias que proporcionaram uma estrutura favorável a que chegassem aos mais altos níveis de instrução. Podemos dizer que pertencem a uma determinada camada abastada da sociedade, ou mesmo a uma elite intelectual da época que talvez tenha garantido o acesso a esta cultura "de ascensão social e esforço, na qual a educação é fundamental, como provaram no curso de suas próprias vidas". (SARLO, 2009, p. 134). Com formação em diferentes licenciaturas, somente Cardeal ressaltou sua experiência na Escola Normal como determinante para a formação em Pedagogia. Foi a partir desta graduação que acabou sendo convidada para realizar a prática educativa no CAp, "para ficar trabalhando, substituindo uma professora da prática de ensino". (CARDEAL, 2015), logo após a conclusão do curso.

As depoentes, formadas em sua maioria pela Ufrgs, realizaram no CAp um "estágio avançado em Didática Geral e Especial" (PARDAL, 2014) que durava um ano. Para Merion Campos Bordas ${ }^{14}$ (2010), "os professores entravam no Colégio de Aplicação como convidados. [...] tendo terminado o curso, eram convidados pela Direção do Colégio, para fazerem um estágio de aperfeiçoamento de ensino. O Colégio era realmente um laboratório". (BORDAS; ANDREOLA, 2010, p. 300). Nesta condição de escola laboratório, até mesmo licenciados em outras Faculdades, como Pardal, eram chamados para a experiência do estágio, "era uma honra [na qual] teríamos um ano bastante fértil com aprendizagens importantes". (PARDAL, 2014).

Mas o que pensar sobre o fato de todas as entrevistadas terem sido convidadas pela Diretora para estagiarem na disciplina que ela lecionava, e permanecerem no Colégio

\footnotetext{
${ }^{14}$ Merion Campos Bordas (1933-2015), professora emérita da Ufrgs, bacharel em Ciências Jurídicas e Sociais e em Filosofia pela Universidade Federal do Rio Grande do Sul, doutora em Educação, foi professora titular do Departamento de Ensino e Currículo da Faced/Ufrgs e colaboradora do Programa de Pós-Graduação em Educação da Ufrgs.
} 
por tantos anos? Ao que tudo indica, Graciema Pacheco procurava moldar as jovens professoras, conforme o que considerava adequado à posição que ocupavam. Cumpre destacar que algumas das estagiárias, ao final de um ano, eram chamadas pela Diretora para trabalharem no CAp como suas assistentes, convite que poderia ser renovado por mais um ano. Ao final do prazo, de acordo com Pardal (2014), a Diretora decidia sobre a permanência dessas professoras na instituição por tempo indeterminado.

As narrativas docentes indicam que a Direção estava imbuída do desejo deque o Colégio se constituísse em um centro de pesquisas, voltado para a produção de investigações que poderiam estimular mudanças educacionais. Pardal explica que Graciema Pacheco foi uma gestora preocupada em pensar a educação de modo crítico e se sentia responsável por multiplicar os resultados de seus estudos. $O$ fato de estagiar no CAp, segundo a entrevistada, não garantia melhores colocações no mercado de trabalho, mas possibilitava que as professoras cultivassem um pensamento reflexivo acerca de suas práticas. Esta característica do Colégio como um lugar onde se viviam e se pensavam os dilemas escolares foi tema recorrente na fala das docentes que avaliam esta concepção como central na construção de uma instituição que se propunha ser um modelo a ser seguido pelas demais.

O convite para o estágio avançado não se restringia apenas às recém-formadas pela Ufrgs, se estendia a professores lotados na rede pública de ensino que iam para o CAp cedidos pela Secretaria de Educação, órgão estadual do qual Graciema nunca se desvinculou completamente. (PILLA, 1956). O objetivo de trazer docentes "da ativa", segundo Rouxinol (2014), era difundir as práticas pedagógicas em voga, que, em sua visão, inspirariam a revisão dos processos escolares, considerando a formação continuada oferecida a esses professores.

Ao que tudo indica, esta Diretora foi alguém que imprimiu uma marca na formação destas e de tantas outras docentes. Esse controle sobre as ações das estagiárias e docentes refletia, inclusive, no modo como deveriam se vestir, pois não podiam, por exemplo, "usar calça comprida, porque a Dona Graciema não queria". (BEM-TE-VI, 2015). Cabe ressaltar que as restrições ao vestuário não eram uma prerrogativa do CAp, faziam parte de um contexto que determinava um modo de comportamento considerado apropriado para a profissão docente feminina.

É preciso atentar que as cinco entrevistadas são filhas de professoras e não tomálo ao simples acaso. Provavelmente, a escolha pela profissão de suas mães está atrelada ao fato do magistério, naquele tempo, ser uma profissão de reconhecimento social para as mulheres, especialmente aquelas oriundas de classe média urbana. Guacira Louro (2001) afirma que havia no imaginário, sobretudo na primeira metade do século $X X$, a concepção de que as mulheres tinham por natureza uma inclinação para o trato com as crianças. Porém, pela incompatibilidade do casamento/maternidade com o exercício da profissão, era comum que muitas professoras abandonassem as salas de aula assim que deixassem de ser solteiras. Essa situação foi observada somente no relato de Rouxinol, ao falar de sua mãe. As demais não conferiram destaque a este aspecto, mas cabe pensar para quantas mulheres esta foi uma realidade. Inclusive, cabe trazer para a cena, mais uma vez, Graciema Pacheco e Isolda Paes, contemporâneas às mães das entrevistadas. A primeira parece ter internalizado a completa entrega ao magistério, pois não casou, nem teve filhos. 
Já Isolda Paes, contraiu matrimônio ${ }^{15}$, na década de 1930, não abandonou a profissão, mas também não teve filhos. Estas são possibilidades de análise a partir do entrelaçamento da fala das narradoras com questões socialmente construídas sobre a profissão docente.

Bem-te-Vi e Rouxinol foram, entre as cinco, aquelas que, além de docentes, também foram alunas do Colégio de Aplicação. Durante as entrevistas, misturaram memórias da vida discente e docente e isso enriqueceu o objetivo do diálogo. No entanto, percebemos distintos modos de narrar o passado em cada uma delas, talvez pela diferença de idade na ocasião do ingresso como estudantes do CAp. Bem-te-vi (2015), aluna da primeira turma, em 1954, falou de um momento em que o CAp iniciava suas atividades em Porto Alegre, ressaltou a proposta pedagógica que se distanciava de um ensino marcadamente tradicional. Segundo a entrevistada, essa primeira turma do Aplicação foi composta por trinta alunos, de ambos os sexos que não haviam sido classificados ${ }^{16}$ no Exame de Admissão ao Ginásio no Instituto de Educação General Flores da Cunha/IE ${ }^{17} \mathrm{e}$ no Colégio Júlio de Castilhos ${ }^{18}$. Contou que, em uma reunião ocorrida no Instituto de Educação (IE), Graciema Pacheco explicou aos presentes que "iam fundar o Colégio de Aplicação, um colégio novo, um colégio diferente, com experiências diferentes, [...] dentro da Universidade". (BEM-TE-VI, 2015). Disse ainda que muitas daquelas crianças eram filhas de mulheres que haviam sido alunas de Graciema no IE, inclusive ela própria.

Estamos falando de uma época em que pairavam dúvidas sobre a implantação do Colégio de Aplicação. Podemos pensar em dois motivos que levaram algumas famílias, em 1954, a matricularem seus filhos em uma instituição que conheciam apenas promessas da Diretora. O primeiro pode ser devido ao prestígio de Graciema Pacheco perante suas exalunas, algumas delas professoras do IE. E o outro motivo, talvez tenha sido o desejo de que os filhos ingressassem logo no ensino ginasial, pois como não haviam sido classificados para as vagas as quais se candidataram, necessitariam, no ano seguinte, prestar novo Exame de Admissão, ou seja, passariam por mais um ano preparatório antes de, efetivamente, ingressarem no Curso Ginasial.

Rouxinol talvez tenha experimentado uma situação diferente ao ingressar como aluna no CAp, em 1966, pois doze anos haviam se passado desde sua fundação. $O$ Colégio, conforme seu relato, já desfrutava de certa notoriedade e estimulava "um ensino ativo, criativo, desafiante". (ROUXINOL, 2014). Comentou que os professores realizavam intercâmbios, dentro e fora do país para conhecerem novas metodologias de ensino que poderiam ser desenvolvidas no CAp. Esse conjunto de ações, que valorizava a formação continuada dos docentes, possivelmente colocava o estabelecimento de ensino em uma posição de destaque na sociedade porto-alegrense. Para muitas famílias, pode ter sido importante os filhos estudarem em uma escola que se caracterizava por uma espécie de vanguarda pedagógica, isso deveria agradar especialmente aqueles que se identificavam com um determinado ethos intelectual.

15 Isolda Holmer casou-se, em 1930, com Elpídio Ferreira Paes, advogado, professor da Faculdade de Direito da Ufrgs. (HACKMANN, 2004).

${ }^{16}$ Os alunos excedentes dos Exames de Admissão ao Ginásio eram todos aqueles que, embora aprovados, não estavam classificados dentro do número de vagas oferecidas pela instituição.

${ }^{17} \mathrm{~A}$ história desta escola remonta à primeira Escola Normal de Porto Alegre no século XIX. Ela tinha o objetivo de preparar professores de ambos os sexos para a instrução primária.

18 Colégio estadual, também conhecido como Julinho, fundado em 1900, ocupou edifício localizado ao lado da Faculdade de Direito da Ufrgs até 1951, quando foi acometido por um incêndio. 
O distanciamento temporal entre o vivido e o recordado, fica mais evidente se atentarmos para o fato de que nenhuma das professoras está mais vinculada ao quadro funcional do CAp. Bem-te-vi foi a primeira a tomar outros rumos na profissão, deixou o Colégio na década de 1970, mas permaneceu ligada à Ufrgs pela Faculdade de Educação, onde esteve até o desligamento total nos anos 1980. As demais, que estavam vinculadas ao CAp e Faced simultaneamente, se afastaram primeiro do Colégio, ao longo dos anos 1980, para se dedicarem exclusivamente à Faculdade de Educação, onde permaneceram até a década seguinte.

Hoje, todas estão longe da Ufrgs. Rouxinol e Bem-te-vi atuam como professoras titulares em Programas de Pós-Graduação (PPG) de Universidades no Rio Grande do Sul e São Paulo. Pardal é colaboradora do PPG de uma Universidade privada de Porto Alegre e Sabiá e Cardeal se afastaram do meio acadêmico; Entretanto, tem-se a impressão de que todas não perderam o vínculo afetivo com a Ufrgs, pois se mostram atentas aos eventos, às pessoas e às discussões presentes na Faculdade de Educação.

É preciso dizer que elaboramos um roteiro de entrevista ${ }^{19}$ que procurasse instigar as depoentes a narrarem experiências vividas no Colégio. A profusão de temas abordados foi fecunda e, assim, identificaram-se práticas educativas desenvolvidas no Colégio de Aplicação sobre as quais pouco conhecíamos, tais como, as Classes Experimentais Secundárias.

\section{Classes Experimentais Secundárias no contexto escolar do CAp/Ufrgs}

Os relatos das entrevistadas e os outros documentos pesquisados apontam para o fato do Colégio Aplicação se diferenciar, sobretudo, pelo caráter experimental presente em suas ações educativas. Naquela temporalidade, pode-se dizer que se caracterizou por ser uma instituição marcada pela investigação do fazer didático, a partir de novos métodos de aprendizagem. Entre estes métodos, destacam-se as Classes Experimentais Secundárias, autorizadas a funcionar a partir de 1961, uma experiência que representava a necessidade de "renovação pedagógica já há muito reclamada por diversos educadores". (AZANHA, 1975, p.44), que objetivava a constituição de um campo de ensaio para aplicação de métodos pedagógicos, bem como de novos tipos de currículos. Por meio dessas Classes, idealizava-se uma escola que conciliasse o desenvolvimento intelectual e as habilidades práticas voltadas para a vida, através de um currículo novo e diversificado nos moldes observados em instituições internacionais. (WARDE, 1995).

Devido à circulação de educadores entre Brasil e França, especialmente, pode-se dizer que as Classes Experimentais brasileiras sejam apropriações ${ }^{20}$ das Classes $^{2}$ Nouvelles francesas. Concebidas no Centre international d'études pédagogiques (Ciep) de

19 roteiro, áudio e transcrição das entrevistas utilizados nesta pesquisa, encontram-se arquivados e disponíveis para consulta no Arquivo da Faced, localizado na Faculdade de Educação: http://www.ufrgs.br/memoriafaced/.

$20 \mathrm{O}$ conceito de apropriação, aqui utilizado, toma por base especialmente os estudos empreendidos por Roger Chartier (2003). Para o autor, tal conceito refere-se aos modos pelos quais o sujeito interpreta informações e as reelabora no sentido de fundamentar ações futuras. Compreende-se, então, que os Colégios de Aplicação brasileiros, amparados pelas articulações dos estudiosos do INEP, ressignificaram práticas e concepções educativas que circulavam em outros países e lhes conferiram novas roupagens, adequadas às necessidades nacionais. 
Sêvres ${ }^{21}$, França, faziam parte das reformulações do Ensino Secundário francês no pósguerra. (LECOQ; LEDERLÉ, 2010). O plano experimental executado no CAp tentava "interpretar as aspirações do grupo pedagógico, docente e discente do Colégio, em ajustada compatibilidade com as exigências do meio e as da nossa conjuntura educacional". (PACHECO, 1961, p.1).

De acordo com Tristan Lecoq e Annick Lederlé (2010), na década de 1940, a França realizou uma grande reforma educacional da qual faziam parte educadores e psicólogos convidados pelo Ministério da Educação Nacional. Este grupo de pesquisadores, entre eles Gustave Monod, Inspetor Geral da Instrução Pública, desenvolveu um novo modelo para o sistema educacional francês, conhecido como Plano Langevin-Wallon ${ }^{22}$. A ideia central da reforma defendia um ensino que oferecesse uma base mínima de conhecimentos aos alunos e, ao mesmo tempo, desenvolvesse a personalidade de cada um. (WEREBE, 1956).

O Centro de Sêvres tornou-se, portanto, uma referência, no qual pesquisadores de diferentes nacionalidades realizaram estágios para melhor conhecer as inovações propostas pela instituição. Isolda Paes, em 1953, um ano antes de assumir a Vice-direção do Colégio de Aplicação, realizou estágio no Centro de Sèvres. É possível inferir que, com essa viagem, ela intencionasse conhecer in loco, os efeitos da reforma educacional francesa e se aproximar das Classes Nouvelles e o Estudo do Meio ${ }^{23}$. (HACKMANN, 2004).

De acordo com Cunha e Abreu (1958), ao mesmo tempo em que os professores estagiavam no Centro de Sèvres, missões francesas tiveram o Brasil como um destino, no intuito de promover intercâmbios entre os dois países. Destaca-se, entre os visitantes, a presença de Madame Edmée Hatinguais, pedagoga, primeira Diretora do Ciepe inspetora geral da Educação Pública francesa que divulgou internacionalmente as ideias do Centro. Ao que tudo indica, a atuação de Edmée Hatinguais no Brasil foi importante não apenas para a divulgação da matriz das Classes Nouvelles, mas para auxiliar no processo de apropriação de tais conceitos entre os educadores nacionais. De acordo com Tamberlini (2001), a pedagoga francesa foi convidada pelo Ministério da Educação brasileiro para proferir um ciclo de palestras relacionadas aos movimentos de renovação do ensino em seu país, processo que culminou na reforma do Ensino Secundário francês, na década de 1940. A autora destaca que as visitas ocorreram na Universidade do Rio de Janeiro, Minas Gerais, São Paulo e Bahia, entre os anos de 1954 e 1956.

Embora não haja informações de outros autores, nem relatórios específicos sobre uma visita de Edmée Hatinguais ao Rio Grande do Sul, há, na Biblioteca do Colégio de Aplicação da Ufrgs, uma fotografia que apresenta a inscrição: "Visita de $\mathrm{M}^{\mathrm{me}}$ Hatinguais -

21 Centro de Sèvres, como também é conhecido, foi criado por Gustave Monod, em 1945, e sucedeu à L'École normale supérieure, destinada a formar professoras.

22 Projeto de reforma de ensino cujo embrião foi idealizado por Gustave Monod. O plano Langevin-Wallon foi pensado a partir das pesquisas de um círculo de psicólogos da infância, entre estes Roger Gal e Henri Wallon. O projeto foi pensado por uma comissão nomeada pelo Ministério da Educação Francês, presidida inicialmente por Paul Langevin e, após sua morte, por Henri Wallon. (STEINDEL; DALLABRIDA; ARAUJO, 2013). A versão final do projeto foi redigida por Wallon e preconizava um ensino que se adequasse às necessidades da sociedade democrática e às características psicológicas de cada sujeito. Contudo, não chegou a ser implantada.

23 O Estudo do Meio, a partir dos estudos do educador francês Célestin Freinet (1896-1966), é método interdisciplinar baseado na vivência do aluno com a realidade sobre a qual se deseja estudar para produzir nele novos conhecimentos. 
agosto 1954". Pode-se pensar então que a Diretora do Ciep circulou, na década de 1950, entre as escolas modelos ligadas ao Inep e que a difusão dos ideais franceses de educação repercutiu na efetivação das Classes Experimentais Secundárias no Brasil. Porém, pensando especificamente na presença de Madame Hatinguais ao CAp de Porto Alegre, no ano de sua fundação, indagam-se os motivos de sua vinda a Porto Alegre, uma cidade, um tanto quanto distante daquelas que costumeiramente recebiam missões pedagógicas estrangeiras. Talvez esta visita se deva às relações firmadas entre ela e a professora Isolda Paes, quando esta esteve na França em 1953. Ou ainda, possa ter ocorrido pelas afinidades de Graciema Pacheco com os educadores ligados ao Ministério da Educação ${ }^{24}$. De qualquer forma, esta visita deve ter repercutido positivamente dentro da Universidade, principalmente por dar visibilidade ao Colégio de Aplicação que começava a se afirmar como uma instituição de ensino promotora de novas experiências educativas em Porto Alegre.

É a partir da década de 1950, que se observa o início de experiências isoladas, claramente inspiradas pelos estudos franceses, como as propostas por Luis Contier em São Paulo. Vale ressaltar que os educadores do Inep, também atentos ao que chegava do estrangeiro, passaram a promover grupos de estudos nas Universidades de São Paulo e Rio de Janeiro para se apropriarem dos referenciais das Classes Nouvelles, por exemplo. Foram estas investidas que permitiram tornar as Classes Experimentais brasileiras, oficiais em 1959, por força de Portaria do MEC. Isso ocorreu cerca de oito anos após a primeira visita de Luis Contier à França e, seis anos após o estágio de Isolda Paes na mesma instituição.

Compete dizer que, conforme ofícios emitidos pela direção da Faculdade de Filosofia da Ufrgs, encontrados no Arquivo da Faced, a professora Graciema Pacheco, esteve mais de uma vez no Rio de Janeiro, para participar de Seminários e Encontros promovidos pelo Inep, para a implantação das Classes Experimentais. Neste sentido, a atuação engajada da educadora naquele órgão deve ter contribuído para disseminar em Porto Alegre o conhecimento sobre as Classes Experimentais Secundárias. De acordo com Sabiá (2015), Graciema lia muitos livros que importava da Europa e Estados Unidos a fim de "compreender e internalizar a informação" sobre as inovações pedagógicas e somente "depois é que ela levava para nós na esperança de que colaborássemos com as novas ideias". (SABIÁ, 2015).

Antes de discorrer acerca das Classes Experimentais no CAp/Ufrgs, convém recordar alguns pontos que facilitaram sua implantação, em 1959, no Brasil. Na esteira do pensamento renovador da educação da primeira metade do século XX, diferentes ações foram implantadas no Brasil, a partir da década de 1930. Entre elas, a criação do Ministério da Educação e Saúde Pública, do Instituto Nacional de Estudos Pedagógicos (Inep), dos Colégios de Aplicação, bem como do Centro Brasileiro de Pesquisas Educacionais (CBPE) e dos Centros Regionais de Pesquisas Educacionais (CRPE) ${ }^{25}$. Estes institutos

24 Ofícios localizados no Arquivo da Faced mostram diversas visitas de Graciema Pacheco ao Ministério da Educação, como convidada, a partir da década de 1950.

25 O Centro Brasileiro de Pesquisas Educacionais foi criado pelo Decreto 38.460 de dezembro de 1955, tendo como localização a cidade do Rio de Janeiro e mais cinco Centros Regionais de Pesquisa Educacional: São Paulo, Minas Gerais, Pernambuco, Rio Grande do Sul e Bahia. Estes órgãos, subordinados ao Inep, tinham o objetivo de investigar e realizar pesquisas e experiências educacionais em nível nacional e regional. Havia também o propósito de reestruturar a educação nacional a partir de um caráter científico e técnico. (NUNES, 
congregavam o pensamento educacional da época, com vistas a promover 0 desenvolvimento nacional. O Centro de Sèvres na Françase destacava por incentivar a pesquisa e o intercâmbio entre intelectuais ligados à educação e pode ser considerado como um dos embriões para a fundação do Centro Brasileiro de Pesquisas Educacionais/CBPE e seus Centros Regionais. Entre as ações incentivadas pelo CBPE, estava a implantação das Classes Experimentais Secundárias no Brasil, como um campo próprio para novas matrizes curriculares.

Importante ressaltar que a Faculdade de Filosofia/Ufrgs possuía com o Inep e com a Secretaria de Educação do Estado do Rio Grande do Sul, acordos de cooperação que transformavam o CAp em um dos campos de estudos e observações de práticas educativas. (CUNHA; PILLA, 1956). Assim, se entende que a emergência dos discursos relacionados às Classes Experimentais esteve atrelada aos modos como as apropriações teórico-metodológicas foram aplicadas.

Pela documentação consultada, é possível inferir que, nos anos de atuação de Graciema Pacheco junto ao Inep, o Colégio de Aplicação e a Faculdade de Filosofia da Ufrgs estiveram em evidência. Neste sentido, em 1959, foi celebrado um acordo especial entre o Inep e a Ufrgs para a manutenção ${ }^{26}$ de um Centro de Pesquisas ${ }^{27}$, integrado ao Departamento de Educação da Faculdade e ao Colégio de Aplicação. Este acordo possibilitou o repasse de verbas à Ufrgs para a construção de um edifício que foi posteriormente ocupado pelo CAp, no Campus Central. A iniciativa proposta pelo acordo visava que a Universidade incorporasse a problemática educacional. (BASTOS; QUADROS; ESQUINSANI, 2006).

Deste modo, o CAp passou a fazer ressoar em Porto Alegre pressupostos educacionais que buscavam atribuir maior sentido às atividades escolares pela "aplicação de novos métodos e processos, bem como o ensaio de novos tipos de currículos". (AMADO, 1958, p.74). Havia certa articulação entre as disciplinas, algo que hoje, podemos considerar como o início de uma prática interdisciplinar diante da fragmentação do conhecimento até então observada.

Entretanto, somente com a Lei de Diretrizes e Bases da Educação Nacional28, em 1961, foi permitido, conforme o Artigo 104, "a organização de cursos ou escolas experimentais, com currículos, métodos e períodos escolares próprios”. (BRASIL, 1961). Esta pode ser considerada, ao menos teoricamente, a efetivação de um ensaio pedagógico que procurava formar integralmente o aluno, para que este se tornasse capaz de atuar na sociedade.

Sobre a questão curricular, as instruções para as Classes Experimentais adotadas pelo Colégio de Aplicação preconizavam que os alunos tivessem oportunidades de maior permanência na escola por meio de atividades extracurriculares e estudos voltados para

2000)

26 Os documentos pesquisados utilizam o termo "manutenção" para o acordo firmado entre Inep e Ufrgs, possivelmente porque o CRPE estava constituído desde 1955 e, somente em 1959, a Ufrgs passou sediar fisicamente o Centro que funcionava até então, na Av. João Pessoa, № 535, conforme pesquisas de Bastos; Quadros; Esquinsani (2006).

27 Essa parceria, prevista no decreto no. 38.460/1955, determinava que esses centros regionais poderiam funcionar em regime de convênios com os governos ou entidades públicas ou privadas ou serem diretamente mantidos e administrados pelo Inep. (BASTOS; QUADROS; ESQUINSANI, 2006).

28 LEI № 4.024, de 20 de dezembro de 1961. 
suas aptidões individuais. (AMADO, 1958). Segundo Rouxinol (2014), o Colégio ofereceria um ensino personalizado no qual o aluno poderia "escolher seu plano de estudos, ou seja, as matérias correspondentes a uma base curricular. [...] havia aulas especializadas como música, datilografia, teatro, artes e as crianças ficavam na escola manhã e tarde". 0 currículo foi organizado em três grupos de disciplinas e atividades tanto para o Ciclo Ginasial quanto para o Colegial, como se observa no quadro a seguir.

Quadro 02 - Currículo das Classes Experimentais - CAp/Ufrgs.

\begin{tabular}{|c|c|c|c|c|c|}
\hline \multirow[b]{2}{*}{ CURSO } & & & \multicolumn{3}{|c|}{ CURRÍCULO } \\
\hline & \multicolumn{2}{|c|}{ DURAÇÃO } & \multirow{2}{*}{\begin{tabular}{l}
\multicolumn{1}{c}{ GRUPOS } \\
CURRICULARES \\
Disciplinas \\
Fundamentais
\end{tabular}} & PLANO A & PLANO B \\
\hline \multirow{3}{*}{ 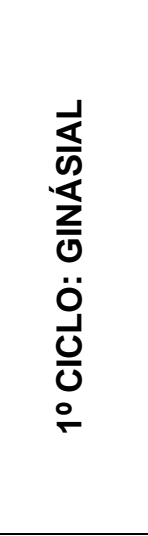 } & \multirow[t]{3}{*}{$\begin{array}{l}4 \\
\text { anos }\end{array}$} & \multirow[t]{3}{*}{$\begin{array}{l}30 \text { horas } \\
\text { semanais }\end{array}$} & & $\begin{array}{l}\text { Português, Matemática, } \\
\text { História, Geografia e } \\
\text { Ciências. }\end{array}$ & \\
\hline & & & Línguas; & Latim, Francês e Inglês. & \\
\hline & & & $\begin{array}{l}\text { Artes e Educação } \\
\text { Física. }\end{array}$ & $\begin{array}{l}\text { Desenho, Música, } \\
\text { Educação Física e Artes } \\
\text { Práticas. }\end{array}$ & $\begin{array}{l}\text { Datilografia, Noções de } \\
\text { Contabilidade, } \\
\text { Estenografia, Desenho, } \\
\text { Artes Domésticas, Artes } \\
\text { Mecânicas, Artesanato } \\
\text { em Geral. }\end{array}$ \\
\hline \multirow{2}{*}{ 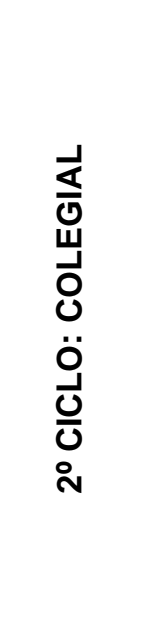 } & \multirow[t]{2}{*}{$\begin{array}{l}3 \\
\text { anos }\end{array}$} & \multirow[t]{2}{*}{$\begin{array}{l}22 \text { horas } \\
\text { semanais }\end{array}$} & Conjuntos Básicos & $\begin{array}{l}\text { Matemática, Física, } \\
\text { Química, Ciências, } \\
\text { Geografia, História, } \\
\text { Língua Estrangeira } \\
\text { Moderna, Literatura, } \\
\text { Filosofia, Artes e } \\
\text { Estudos Clássicos. }\end{array}$ & \\
\hline & & & $\begin{array}{l}\text { Cursos } \\
\text { Integradores }\end{array}$ & $\begin{array}{l}\text { Problemas Modernos, } \\
\text { Estudos Brasileiros, } \\
\text { Estudo do Social e do } \\
\text { Econômico, Introdução } \\
\text { à Psicologia e História } \\
\text { da Religião. }\end{array}$ & \\
\hline
\end{tabular}

Fonte: Construção das autoras com base nas informações no Plano para Organização de uma Classe Experimental para o 1ํㅡㄹ Ciclo Secundário, do CAp/Ufrgs. (PACHECO, 1961).

Em tese, o currículo foi idealizado para que o estudante desenvolvesse uma relativa autonomia, guiado pelo Serviço de Orientação Educacional e pela família. O Plano A direcionava para uma formação humanística, destinada àqueles que desejavam prosseguir no segundo ciclo do Ensino Secundário "nas Escolas Normais e em outros estabelecimentos que exijam essa forma de preparo propedêutico". (PACHECO, 1961, p.2). Já, o Plano B, que previa disciplinas como Noções de Contabilidade e Artes Mecânicas, voltava-se para "atender às vocações de caráter prático e a necessidade de trabalho". (PACHECO, 1961, p.2) dos jovens que talvez não seguissem imediatamente o segundo 
ciclo Secundário. Havia, neste caso, a preocupação de que o estudante fosse devidamente instrumentalizado para seguir atividades comerciais, artísticas ou industriais, a fim de qualificar de forma especializada a mão de obra que atenderia à demanda do mercado de trabalho.

Conforme os documentos pesquisados, incluindo as narrativas orais, entende-se que o propósito das classes experimentais era que os alunos atingissem os melhores rendimentos, por meio de um ensino centrado nas potencialidades de cada sujeito. Mas como estas potencialidades seriam desenvolvidas dentro do Colégio? Para Pardal (2014), naquele contexto de experimentação, isso acontecia por meio da pesquisa que, segundo a professora, era "algo natural" na instituição. As docentes ministravam suas aulas e, paralelamente, produziam investigações. Observavam e analisavam os alunos em diferentes quesitos e os orientavam para os estudos, alinhados ao perfil individual.

Portanto, no intuito de alcançar o sucesso das Classes Experimentais no CAp, foi necessário que o corpo docente conhecesse as características das Classes Nouvelles francesas, no sentido de aperfeiçoar a experiência a ser realizada. Os princípios e métodos adotados pelo Colégio de Aplicação tendiam a ser uma mescla da normatização francesa e brasileira, observadas no próximo quadro que apresenta características dos dois enfoques.

Quadro 03 - Princípios gerais das Classes Nouvelles francesas e Classes Experimentais brasileiras.

\begin{tabular}{|l|l|}
\hline \multicolumn{1}{|c|}{ CLASSES NOUVELLES FRANCESAS } & \multicolumn{1}{c|}{ CLASSES EXPERIMENTAIS BRASILEIRAS } \\
\hline Limitação do efetivo a 25 alunos; & Classes no máximo de 30 alunos; \\
\hline $\begin{array}{l}\text { Número reduzido de professores com a turma ao } \\
\text { longo dos anos; }\end{array}$ & $\begin{array}{l}\text { Classes iniciais do ginásio com número de } \\
\text { professores reduzido, no sentido de evitar uma } \\
\text { transição abrupta do primário para o secundário; }\end{array}$ \\
\hline $\begin{array}{l}\text { Fichas de observações detalhadas pelo professor } \\
\text { da personalidade e comportamento de cada aluno; }\end{array}$ & $\begin{array}{l}\text { Nos currículos ter-se-ia em vista, basicamente, a } \\
\text { preparação geral, com sólido conteúdo formador e } \\
\text { margem a maior atendimento às diferentes } \\
\text { aptidões individuais; }\end{array}$ \\
\hline Métodos ativos personalizados e cooperativos & Participação ativa do aluno no trabalho escolar; \\
\hline $\begin{array}{l}\text { Visitas a diferentes lugares visando à observação } \\
\text { do meio; }\end{array}$ & $\begin{array}{l}\text { Permanência diária dos alunos na escola suficiente } \\
\text { para participação nas atividades extraclasses; }\end{array}$ \\
\hline Trabalho dirigido; & $\begin{array}{l}\text { Horários ensejando possibilidades de opç̃̃es } \\
\text { correspondentes às aptidões dos alunos; }\end{array}$ \\
\hline $\begin{array}{l}\text { Reduzir a dicotomia entre o trabalho manual e o } \\
\text { trabalho intelectual; }\end{array}$ & $\begin{array}{l}\text { Reuniões periódicas dos professores de cada } \\
\text { classe, para lhe apreciar os aspectos psicológicos } \\
\text { e pedagógicos e dar melhor orientação; }\end{array}$ \\
\hline $\begin{array}{l}\text { Ênfase ao trabalho em equipe em detrimento ao } \\
\text { trabalho em grupo; }\end{array}$ & $\begin{array}{l}\text { Articulação no ensino das várias disciplinas e } \\
\text { coordenação das atividades escolares; }\end{array}$ \\
\hline Ciclo de orientação e observação; & Articulação estreita entre pais e professores. \\
\hline
\end{tabular}

Fonte: Construção das autoras, a partir de Lecocq; Lenderlé (2010) e Amado (1958).

É possível identificar semelhanças que reproduziam a experiência francesa quase diretamente para as normativas brasileiras, como no caso do número médio de discentes em sala de aula, que não deveria exceder a trinta. Possivelmente, o interesse por manter 
menos alunos em sala de aula buscava promover uma dinâmica de sala de aula em que a efetiva participação dos estudantes pudesse ocorrer. Desta forma, a docente teria oportunidade de acompanhar mais detidamente cada jovem. Tal orientação estava em consonância com os ideais renovadores da época, que envolviam tanto franceses quanto brasileiros.

As narrativas orais atentam de modo positivo para esse conhecimento, difundido nacionalmente sobre o que era praticado no Centro de Sèvres. Escolas brasileiras, como o CAp/Ufrgs, se apropriaram de princípios da experiência francesa e os aplicaram de modo articulado ao proposto pelo MEC. Conforme Rouxinol (2014), as Classes Experimentais não previram, por exemplo, a realização de passeios para o Estudo do Meio, como visto no item francês Visitas a diferentes lugares visando à observação do meio. Contudo, esta prática já era realizada no CAp, desde sua fundação. Segundo Isolda Paes (1983), atividades "inspiradas na experiência francesa do estudo do meio" (p.76) aconteciam sistematicamente com a finalidade de sair "com os alunos pela cidade, para que eles vissem coisas, para que entrassem em contato com as pessoas". (PACHECO, 1974, p.19).

As entrevistadas indicam que, além do Estudo do Meio, o Trabalho Dirigido29também se fazia presente. Para Sabiá (2015), esta metodologia de ensino fez parte das práticas presentes no CAp e procurava que o aluno se "investisse de ímpeto pela leitura e, consequentemente, pela pesquisa" (2015), pois isso o levaria a adquirir melhores hábitos de estudo. Desta forma, Pardal (2014) recorda que esta "foi uma belíssima experiência, [...] o estudo através de fichas, o material instrucional" que faziam parte da Pesquisa Individualização do $\mathrm{Ensino}^{30}$, coordenada pela professora Louremi Ercolani Saldanha.

Neste projeto, observa-se, mais uma vez, a marca da Psicologia, que ditava princípios e guiava "experiências realizadas em laboratórios" (SALDANHA, 1969, p.15), no caso do CAp, uma escola-laboratório. Esta experiência representava uma tentativa de levar os estudantes a alcançarem os objetivos educacionais, pelo "agrupamento de certas operações mentais, utilizando uma metodologia didática que enfatiza o desenvolvimento pessoal". (SALDANHA, 1969, p.9). O discurso da Psicologia, estava presente no CAp desde sua fundação, em 1954, e procurava colocar em ação o princípio da inviabilidade do ensino homogeneizado, tendo em vista as especificidades de cada aluno. Vale lembrar que o Colégio anualmente fazia o levantamento destas especificidades, a partir dos testes psicológicos aplicados na seleção dos estudantes.

Ao escutar as entrevistadas, ainda é possível estabelecer mais uma aproximação entre a experiência do Colégio de Aplicação de Porto Alegre e as Classes Nouvelles francesas. De acordo com as narrativas, a manutenção de reduzido no número de docentes por turma promovia uma transição mais tranquila do Ensino Primário para o Ginasial. Conforme Pardal (2014), os estudantes estavam acostumados a interagir com poucos professores diariamente, ao ingressarem no Curso Ginasial, se deparavam com "um

29 O Trabalho ou Estudo Dirigido é uma técnica fundamentada no princípio didático de que o professor não ensina, mas orienta e auxilia o aluno no processo de aprender. Desta forma, coloca em evidência o modo como o aluno aprende e incentiva a atividade intelectual dele, forçando-o à descoberta de seus próprios recursos mentais. (CASTRO, 1965).

30 Modêlo de Organização do Ensino com Vistas à Individualização. Pesquisa patrocinada pelo Centro Regional de Pesquisas Educacionais do Rio Grande do Sul/Inep/MEC. Supervisora geral da pesquisa: Prof ${ }^{a}$ Graciema Pacheco, diretora do Colégio de Aplicação. (SALDANHA, 1969). 
docente para cada disciplina e nem todas as crianças se adaptavam, algumas até se sentiam intimidadas". Para ela, essa foi a base para a experiência denominada sexto ano polivalente, desenvolvida no Colégio, a partir da década de 1960.Assim, no sexto ano polivalente, uma única professora, a polivalente, coordenava a turma e era responsável por ministrar aulas de Português, Matemática, Ciências, Geografia e História. Além da polivalente, havia docentes especializados de Educação Física e Teatro.

A designação, Sexto Ano Polivalente, os motivos para sua instalação e o público a que se destinava merecem ser esclarecidos neste contexto. A Lei de Diretrizes e Bases da Educação de 1961 determinava que o Ensino Primário tivesse no mínimo, quatro séries elementares que poderiam ser estendidas por mais duas, complementares. Estas últimas séries, quinta e sexta, deveriam ser ministradas àqueles que não iniciassem o Ensino Ginasial após o término do quarto ano primário e objetivava a ampliação dos conhecimentos do aluno "iniciando-o em técnicas de artes aplicadas, adequadas ao sexo e à idade". (BRASIL, 1961, p.6). Para os alunos que cursavam as séries complementares, conforme a legislação era permitido o ingresso na $2^{\underline{a}}$ série Ginasial, mediante aprovação em novo Exame de Admissão.

Segundo Pardal (2014), o CAp idealizou uma espécie de sexta série primária, oferecida aos trinta candidatos suplentes da prova do Exame de Admissão de 1963. Esses estudantes da "Classe Experimental Paralela" (CARDEAL, 2015), por não terem sido aprovadas no Exame de Admissão, não estavam formalmente cursando o Ginásio, entretanto, vivenciavam as mesmas práticas oferecidas na $1^{\underline{a}}$ série Ginasial. No ano seguinte, após a aprovação em novo Exame de Admissão prestado, seriam matriculados na $2^{\text {a }}$ série Ginasial, como previa a legislação.

As aulas seriam ministradas, em "caráter experimental [...] vis-à-vis à 1a série ginasial, mas com [...] professora polivalente". Com isso, o currículo das Classes Experimentais que já estava sendo trabalhado no Ginásio, foi ampliado para atender aos candidatos que não lograram êxito nos Exames de Admissão, deste modo, sessenta e seis discentes ingressaram naquele ano. Metade deles, na 1a série Ginasial Experimental regular e a outra metade, na turma polivalente.

Vera Moraes, primeira Diretora eleita após a aposentadoria de Graciema Pacheco, em artigo à Revista do CAp destacou que "os bons resultados obtidos nessa experiência". (MORAES, 2004, p.27), conduziram a escola a repetir a prática, a partir de 1965. Ao invés de ingressarem apenas trinta alunos, iniciaram sessenta estudantes que experimentaram um "currículo ministrado por uma única professora que dava as cinco disciplinas: Português, História, Geografia, Biologia e Matemática”. (PARDAL, 2014). Segundo Rouxinol (2014), as professoras polivalentes recebiam orientações para ministrar disciplinas que não faziam parte de sua formação inicial. Pela manhã, elas ministravam suas aulas e a tarde, enquanto "os alunos tinham aulas de teatro, música, artes, educação física e outras coisas, a professora polivalente [...] ficava sendo assessorada pelas professoras das áreas [...]" (ROUXINOL, 2014).

Como demonstrado até este momento, boa parte das práticas educativas presentes no CAp estavam envoltas pelos ideais pedagógicos renovadores difundidos na França e imbuídas do objetivo de se constituir em um campo de pesquisa educacional brasileiro. Desta forma, havia naquele contexto, a preocupação de conhecer o aluno, mapear seu desenvolvimento e, com base nos resultados, refletir e discutir com outros profissionais 
sobre as possibilidades educativas que levassem o Colégio a oferecer um ensino qualificado para seus estudantes.

\section{Considerações finais}

Para compreender este "colégio diferente", com "práticas diferentes", nos dizeres de Bem-te-vi (2015), foi preciso considerá-lo na sua complexidade e integrá-lo a um contexto mais amplo, pois esta instituição não é uma ilha. A confluência dos discursos, da legislação e dos ventos estrangeiros que sopraram para o Brasil, aliados à idealização de outro tipo de escola, fomentaram o estabelecimento de diferentes modos de se pensar as práticas educativas.

Podemos dizer, assim, que a criação dos Colégios de Aplicação, a partir de 1946 e respaldada pelo Ministério da Educação, foi um conceito de escola gestado dentro do escolanovismo. Mas este ímpeto escolanovista não estava presente apenas em grandes centros distantes de Porto Alegre. Aqui, tivemos pessoas como Graciema Pacheco, Isolda Holmer Paes e tantas outras, quase anônimos, que desenvolveram experiências consideradas promissoras para o ensino-aprendizagem.

Desta forma, legitimou-se a concepção do Colégio de Aplicação, como uma escola exemplar que pretendia propagar suas práticas para outras instituições de ensino. Apostava-se no sucesso dos estudantes, e no incentivo à formação pedagógica dos docentes. Contava-se com o apoio das famílias que se identificavam com um determinado ethos intelectual, próprio de uma escola que anunciava uma vanguarda pedagógica.

Diante de tudo o que foi pesquisado, percebe-se o quanto o Colégio insistia no ideal de perfeição. Foi administrado pela mesma pessoa, que, ao que tudo indica, centralizou as ações administrativas e pedagógicas, por quase trinta anos. O CAp tinha como princípio constituir um aluno em nível de excelência, recebendo apenas aqueles que se destacavam nas avaliações.

Entretanto, é preciso dizer que, o Colégio aqui apresentado é produto do seu tempo e representa a circularidade cultural vivida pelos educadores, especialmente franceses e brasileiros que, por muitos anos, estiveram ligados pelas missões e intercâmbios pedagógicos. Estas relações parecem ter sido cruciais para o desenvolvimento das Classes Experimentais no Brasil e, sobretudo, no Aplicação, que contava com a Vice-Diretora, Isolda Holmer Paes, uma estudiosa da educação e da cultura francesa.

As Classes Experimentais representaram uma apropriação das teorias das Classes Nouvelles, ao difundirem nacionalmente práticas que procuravam envolver o aluno em seu processo de aprendizado. Diante dos materiais analisados, procurou-se identificar aquilo que permitiu refletir não apenas sobre os temas abordados pelas entrevistadas, mas também sobre esta pluralidade de discursos que influenciaram no modo como o CAp se constituiu. Podemos dizer que o Colégio assumiu um papel que foi socialmente atribuído a ele e se organizou tendo por fundamento este ideal.

Entre a Memória Oral e o Arquivo, este estudo pretendeu contribuir na produção do conhecimento em História da Educação, de forma a dar visibilidade a experiências pedagógicas, que materializaram um modo de pensar o fazer educacional. Além disso, buscou-se compreender esta instituição de ensino e sua cultura escolar, que promoveu a difusão de importantes práticas educativas. Ainda há muito que ser dito, pois sabemos que 
a memória é composta por "pedaços do passado" (ALBERTI, 2004, p.15) feitos tanto de lembranças quanto de esquecimentos.

\section{Referências}

ALBERTI, Verena. Manual de História Oral. 3. ed. Rio de Janeiro: FGV, 2004.

ALMEIDA, Dóris Bitencourt.; LIMA, Valeska. O Colégio de Aplicação da Ufrgs e suas precursoras: memórias apagadas (1954-1996). Conjectura: Filosofia e Educação (UCS), v. 20, p. 141-163, 2015.

AMADO, Gildásio. Instruções sôbre a natureza e a organização das classes experimentais, da Diretoria do Ensino Secundário. Classes Experimentais no Ensino Secundário. Revista Brasileira de Estudos Pedagógicos, n. 72, v. XXIX, p. 73-83, abr./jun. 1958.

AZANHA, José Mário P. Experimentação educacional, uma contribuição para sua análise. São Paulo: Edart,1975.

BASTOS, Maria Helena Câmara; QUADROS, Claudemir de; ESQUISANI, Rosimar Serena Siqueira. Luzes e sombras de um projeto. In: ARAÚJO, Marta Maria de; BRZEZINSKI, Iria (Orgs.). Anísio Teixeira na direção do Inep: Programa para a reconstrução da nação brasileira (1952-1964). Brasília: Instituto Nacional de Estudos e Pesquisas Educacionais Anísio Teixeira, 2006.

BEM-TE-VI. Entrevista concedida à autora. 2015.

BRASIL. Lei no 4.024, de 20 de dezembro de 1961.Fixa as Diretrizes e Bases da Educação Nacional. Disponível em: <http://www.mec.gov.br/>. Acesso em: 10 dez. 2015.

BRASIL. Decreto no 39.900, de 15 de março de 1962. Dispõe sobre a instalação de cursos preparatórios de admissão junto aos Estabelecimentos oficiais de ensino secundário.

CARDEAL. Entrevista concedida à autora. 2015.

CAP. [Informativo interno] Sistema de Avaliação, 1974.

CHARTIER, Roger. Leituras e leitores na França do Antigo Regime. Tradução de Álvaro Lorencini. São Paulo: UNESP, 2003.

CUNHA, Gilberto; PILLA, Raul. [Ofício] Acordo: celebrado entre a Secretaria de Educação e Cultura e a Faculdade de Filosofia da Ufrgs, 1956.

CUNHA, Nádia; ABREU, Jayme. Classes secundárias experimentais - balanço de uma experiência. Revista Brasileira de Estudos Pedagógicos, Rio de Janeiro, Instituto Nacional de Estudos Pedagógicos, v. XL, n. 91, jul./set.1963.

FOUCAULT, Michel. Ditos e Escritos III, 1977.

GATTI JÙNIOR, Décio. A história das instituições educacionais: inovações paradigmáticas e temáticas. In: ARAUJO, José Carlos Souza; GATTI JR., Décio (Orgs.). Novos temas em história da educação brasileira: instituições escolares e educação na imprensa. Uberlândia: Edufu, 2002.

GOMES, William B. Pesquisa e prática em psicologia no Brasil. 2003. Disponível em: <http://www.ufrgs.br/museupsi/ppnb.htm>. Acesso em: 13 mar. 2013.

HACKMANN, Berenice Gonçalves. Isolda Holmer Paes: a constante aprendiz, a eterna educadora. In: ABRAHÃO, Maria Helena Menna Barreto (Org.). Identidade e vida de educadores rio-grandenses: narrativas na primeira pessoa (e em muitas outras). Porto 
Alegre: Edipucrs, 2004. p. 117-142.

LECOQ, Tristan; LEDERLE, Annick. Le Centre international d'études pédagogiques à

Sèvres: une histoire plurielle d'unlieu singulier. Sèvres: Centre International d'Études Pédagogiques, 2010.

MAGALHÃES, Justino. Tecendo nexos: história das instituições educativas. Bragança Paulista/SP: Editora Universitária São Francisco, 2004.

MORAES, Vera Regina Pires. Colégio de Aplicação 1981-1984: um inventário de vida. Cadernos do Aplicação, Porto Alegre, v. 17, n. 1/2, p. 27-36, jan./dez. 2004.

NUNES, Clarice. Trajetória intelectual e identidade do educador: Anísio Teixeira (19001971). Revista Brasileira de Estudos Pedagógicos, Brasília, v. 81, n. 197, p. 154-166, jan./abr. 2000. Disponível em: <http://www.publicacoes.inep.gov.br/arquivos/rbep197_ 299.pdf>. Acesso em: 21 jul. 2015.

PACHECO, Graciema. [Informativo interno] Plano para organização de uma classe experimental para o $1^{\circ}$ ciclo secundário, 1961.

No Colégio de Aplicação perseguimos a excelência. Correio do Povo, Porto Alegre, 5 de maio de 1974.

PAES, Isolda Holmer. Depoimento da professora Isolda Paes: mensagem a professores e alunos. Cadernos do Aplicação, Porto Alegre, v. 7, n. 1, p. 17-20, jan./jun. 1994.

Colégio de Aplicação: naqueles primeiros dias. Educação \& Realidade, Porto Alegre, v. 8, n. 1, p. 75-81, jan./abr. 1983.

PARDAL. Entrevista concedida à autora. 2014

REGNER, Anna Carolina Krebs Pereira. IFCH: Origens e trajetórias. Da criação da Faculdade de Filosofia à década da Reforma Universitária. In: 50 anos da Faculdade de Filosofia: publicação comemorativa. Porto Alegre: Ufrgs, 1993. 133 p.

ROCHA, Any Dutra. Conselho de classe: burocratização ou participação? Rio de Janeiro: Francisco Alves, 1982.

ROUXINOL. Entrevista concedida à autora. 2014.

SABIÁ. Entrevista concedida à autora. 2015.

SALDANHA, Louremi Ercolani. Ensaio sobre um modelo de organização do ensino com vistas à individualização. Porto Alegre: CRPE, Inpe, 1969. 2 v.

STEINDEL, Gisela Eggert; DALLABRIDA, Norberto; ARAUJO, Elisabete Maria de.

Gustave Monod e as classes nouvelles: apropriações e renovações no ensino secundário francês. In: COLÓQUIO ENSINO MÉDIO, HISTÓRIA E CIDADANIA, VIII, 2013, Florianópolis/SC. Anais... Florianópolis: Universidade do Estado de Santa Catarina/Udesc, 2013, v. 3. p. 01-12.

TAMBERLINI, Ângela Rabello Maciel de Barros. Os Ginásios vocacionais, a história e a possibilidade de futuro. Ensino Vocacional: uma pedagogia atual. São Paulo: Cortez, 2001. p. 15-24.

WARDE, Mirian Jorge. O Colégio de Aplicação da Universidade de São Paulo. In: GARCIA, Walter Esteves (Org.). Inovação educacional no Brasil: problemas e perspectivas. 2ed.São Paulo: Cortez, 1995. p. 101-131.

WEREBE, Maria José G. A renovação pedagógica em França. Revista de Pedagogia, São Paulo, Edusp, v. 2, ano 2, n. 1, p. 57-68, jan./jun. 1956. 
VALESKA ALESSANDRA DE LIMA é graduada em Pedagogia, mestre em Educação, professora do Ensino Fundamental.

Endereço: Rua Oscar Schneider, 422 - ap. 104, 90880-410, Porto Alegre/RS, Brasil.

E-mail: vlima.crk@gmail.com

DORIS BITTENCOURT ALMEIDA é professora de História da Educação da Faculdade de Educação e do Programa de Pós-graduação em Educação da Universidade Federal do Rio Grande do Sul (Ufrgs).

Endereço: Rua Lopo Gonçalves, 218 - ap. 601, 90050-350, Porto Alegre/RS, Brasil.

E-mail: almeida.doris@gmail.com

Recebido em 18 de outubro de 2017.

Aceito em 26 de junho de 2018. 